\title{
UMA AVALIAÇÃO DA CAPACIDADE DE TRANSMISSÃO DE VOZ EM REDES 802.11 NO MODO AD HOC
}

\author{
Pedro Braconnot Velloso, Marcelo G. Rubinstein e Otto Carlos M. B. Duarte
}

\begin{abstract}
Resumo - Este artigo apresenta uma análise da capacidade de transmissão de voz em redes ad hoc, levando em consideração parâmetros de qualidade como o atraso, a variação do atraso, a taxa de perda e as perdas consecutivas. A análise permite avaliar a influência da mobilidade e da provisão de qualidade de serviço no número de fontes transmitindo voz. Outra questão analisada é o efeito da variação da densidade de nós da rede. Os resultados mostram ser possível aumentar em até $22 \%$ a capacidade de transmissão de voz ao se reduzir o tempo de acesso ao meio, através da diferenciação de serviço na camada de acesso ao meio. Além disso, a variação, tanto da mobilidade quanto da carga da rede, provoca uma degradação de até $60 \%$ na capacidade da rede de transmitir voz, principalmente em redes móveis de múltiplos saltos.
\end{abstract}

Palavras-chave: Redes sem fio ad hoc, IEEE 802.11, transmissão de voz e mobilidade

Abstract - This paper analyzes voice transmission capacity on ad hoc networks by performing simulations related to delay, jitter, loss rate, and consecutive losses. We evaluate the influence of mobility and quality of service provisioning on the number of voice transmitting sources. Another issue addressed in this paper is the effect of node density in voice transmission. Results show that we can achieve up to $22 \%$ of improvement in the capacity of voice transmission when the medium access time is reduced by service differentiation on the MAC layer. Moreover, mobility and network load variations can degrade up to $60 \%$ the network capacity of voice transmission, mainly on multihop mobile networks.

Keywords: Wireless ad hoc networks, IEEE 802.11, voice transmission, and mobility

\section{INTRODUÇÃO}

A comurnicação sem fio permite a mobilidade, proporcionando uma maior flexibilidade, além de possuir um baixo custo de instalação se comparado ao custo das redes com fio. Por isso, a utilização de redes locais sem fio tem apresentado um grande crescimento nos últimos anos. As redes sem fio são divididas em duas categorias. A primeira abrange as redes com infra-estrutura, nas quais toda a comunicação é realizada através de um ponto de acesso, como é o caso das redes celulares de telefomia. A segunda categoria engloba as redes

Pedro Braconnot Velloso e Otto Carlos M. B. Duarte são do PEECOPPE/DEL-POLI da Universidade Federal do Rio de Janeiro e Marcelo G. Rubinstein é do Depto. de Eng. Eletrônica e Telecomunicaçōes da Faculdade de Engenharia da Universidade do Estado do Rio de Janeiro, Rio de Janeiro, RJ, Brasil. E-mails: \{pvelloso, otto\}@gta.ufrj.br, nubi@uerj.br. sem infra-estrutura, também denominadas redes ad hoc, nas quais as estações se comunicam diretamente, não existindo o ponto de acesso. Nas redes ad hoc de comunicação direta os nós podem se comunicar, única e exclusivamente, com os nós que estão dentro do seu raio de cobertura. Por sua vez, nas redes ad hoc de múltiplos saltos, as estações da rede também se comportam como roteadores, permitindo a comunicação entre os nós cuja distância ultrapassa o raio de cobertura, mas em consequiência, são bem mais complexas.

As redes ad hoc apresentam diversas vantagens como, por exemplo, a grande flexibilidade, pois podem ser formadas rapidamente mesmo em lugares ermos, o baixo custo de instalação e a robustez, pois podem resistir a catástrofes da natureza e a situações de destruição por motivo de guerra. Desta maneira, as principais aplicações para redes ad hoc são em ambientes onde não há qualquer tipo de infra-estrutura de comunicação, ou esta seja economicamente inviável, ou ainda, caso a infra-estrutura existente não seja confiável, como é o caso de operações militares em teritólio inimigo.

A grande desvantagem das redes ad hoc, sobretudo das redes de múltiplos saltos, é o fato das estações serem mais complexas, isto porque além de ter que implementar um mecanismo específico de controle de acesso ao meio e mecanismos para evitar os problemas de terminais expostos e escondidos, cada nó deve agir como um roteador. Além disso, adicionam-se todos os problemas relacionados às redes sem fio, como por exemplo, a baixa taxa de transmissão, a alta probabilidade de erro e a grande variação das condições do meio de transmissão. Esta complexidade toma a transmissão de voz em redes ad hoc um grande desafio.

A pesquisa na área de qualidade de serviço (QoS - Quality of Service) em redes ad loc abrange diversos tópicos que incluem roteamento com $\operatorname{QoS}[1,2,3]$, modelos de $\operatorname{QoS}[4,5]$, sinalização $[6,7,8]$ e QoS na camada de controle de acesso ao meio $[9,10]$. Bharghavan et al. [1] propuseram um protocolo de roteamento (CEDAR - Core-Extraction Distributed ad hoc Routing) capaz de prover QoS em redes ad hoc. O CEDAR é baseado na eleição de líderes responsáveis por realizar o roteamento e propagar apenas as rotas mais estáveis. Xiao et al. [4] propuseram um modelo flexível de QoS para redes móveis ad hoc, que consiste em um modelo híbrido entre o DiffServ (Differentiated Services) e o IntServ (Integrated Services). O INSIGNIA, proposto por Campbell et al. [6], é um protocolo de sinalização que provê suporte a QoS em redes móveis ad hoc. Em [9, 10], foram apresentados os principais problemas referentes à provisão de diferenciação de serviço em redes locais sem fio que seguem o padrão IEEE 802.11. Também foram avaliadas, por meio de simulações, as principais técnicas de diferenciação de serviço na camada de controle de acesso ao meio (MAC Medium Access Control). Os resultados obtidos nestes tra- 
ballios mostraram ser possível prover prioridades no acesso ao meio em redes ad loc através da modificação do valor do DIFS (Distributed Inter-Frame Space), da janela de tempo do backoff e do tamanho do quadro a ser transmitido.

A transmissão de voz em tempo real deve obedecer a certos requisitos de qualidade de serviço devido a características intrínsecas a este tipo de tráfego. Existem alguns trabalhos que analisam a capacidade de transmissão de voz em redes infra-estruturadas baseadas no padrão IEEE 802.11. Köpsel e Wolisz [11] realizaram simulações para avaliar o efeito da taxa de erro binária (BER - Bit Error Rate) no atraso do acesso ao meio e no goodput em redes com infra-estrutura, mostrando que a elevação da taxa de enro provoca um aumento considerável no atraso de acesso ao meio. Isto se deve ao aumento do espaçamento entre quadros (Inter-Frame Space), pois este parâmetro varia de acordo com a taxa de erro do canal. Wolisz et al. [12] analisaram a capacidade do padrão 802.11 en relação ao número de estações transmitindo voz em redes infra-estruturadas. Esse trabalho avalia, através de simulações, o ponto ótimo de cliaveantento entre os mecanismos de controle de acesso DCF (Distributed Coordination Function) e o PCF (Point Coordination Function), tendo em vista que o PCF apresenta um melhor desempenho em redes com maior carga. A partir dos resultados obtidos, os autores propuseram um mecanismo híbrido de acesso ao meio que utiliza o DCF e o PCF.

O principal objetivo deste artigo é realizar uma análise da capacidade de transmissão de voz em redes ad hoc, levando em consideração parâmetros como o atraso, a variação do atraso e a taxa de perda, revelando aspectos específicos deste tipo de rede. A análise abrange aspectos relacionados ao efeito da mobilidade e à provisão de qualidade de serviço na camada MAC [13, 14]. Além disso, foi realizada uma análise da influência da densidade de nós da rede no tráfego de voz, assim como, uma análise do comportamento das perdas de pacotes em rajadas em redes 802.11, no modo ad hoc.

Este trabalho está organizado da seguinte forma. Na Seção 2 são apresentados os requisitos básicos para transmissão de voz. Na Seção 3 são apresentadas as principais caractelísticas da camada MAC do padrão IEEE 802.11 e são descritos os principais mecanismos propostos para prover qualidade de serviço em redes IEEE 802.1 I. Detalhes referentes às simulações e à análise dos resultados são apresentados na Seção 4. Por fim, na Seção 5 são apresentadas as conclusōes e os trabalhos futuros.

\section{OS REQUISITOS DO TRÁFEGO DE VOZ}

A transmissão de voz por pacotes em tempo-real deve satisfazer alguns requisitos, como por exemplo, garantir um atraso máximo para cada pacote, uma variação máxima do atraso dos pacotes e uma taxa máxima de perda de pacotes. Dentre estes parâmetros, $o$ atraso é o que mais contribui para a perda da interatividade da conversação. Na Tabela 1 são apresentados alguns valores de tolerância ao atraso recomendados pelo ITU-T [15]. O atraso total é composto, basicamente, pela soma de quatro parcelas: o atraso da codificação e decodificação, o atraso da geração de pacotes, o atraso de propagação e o atraso da espera em filas. Na Internet, quando a rede está congestionada, $o$ atraso devido à espera em filas representa a maior parte do atraso total. Entretanto, em redes sem fio, na presença de diversas estações transmitindo simultaneamente, o tempo de acesso ao meio contribui significativamente para o aumento do atraso, refletindo em um aumento do transbordo das filas da camada MAC das estações da rede.

Tabela 1. Tolerância ao atraso em comunicações de voz.

\begin{tabular}{|c|l|}
\hline Atraso da voz & \multicolumn{1}{|c|}{ Tolerância } \\
\hline até 150ms & Aceitável com boa interatividade \\
\hline $150 \mathrm{~ms}-400 \mathrm{~ms}$ & $\begin{array}{l}\text { Aceitável, mas o usuário já } \\
\text { percebe alguma perda de } \\
\text { interatividade }\end{array}$ \\
\hline acima de $400 \mathrm{~ms}$ & $\begin{array}{l}\text { Inaceitável, conı perda de } \\
\text { interatividade }\end{array}$ \\
\hline
\end{tabular}

O tráfego de voz, ao contrário do tráfego de dados, admite a ocorrência de perdas de pacotes, contudo, existe um certo limite para a taxa de perda, de modo a não prejudicar a inteligibilidade. Outro fator relevante para a transmissão de voz é o número de pacotes consecutivos perdidos em um mesmo fluxo, pois a perda de pacotes consecutivos é mais prejudicial que a perda de pacotes intercalados.

A variação do atraso também pode degradar a qualidade da voz transmitida, pois a reprodução de um tráfego de voz deve ser feita de forma cadenciada. Para resolver este problema são utilizados buffers no receptor para armazenamento da voz antes de sua reprodução. Portanto, o aumento da variação do atraso implica um aumento do tamanho do buffer.

\section{QoS EM REDES AD HOC}

O IEEE 802.11 [16] é um padrão para redes locais sem fio que cobre tanto a camada física quanto a camada enlace (MAC). A camada MAC possui dois mecanismos de controle de acesso ao meio, o DCF e o PCF. O primeiro é um mecanismo distribuído, no qual cada elemento da rede deve escutar o meio e transmitir apenas quando o meio estiver vazio. O PCF é um mecanismo centralizado onde o ponto de acesso controla o acesso ao meio e, portanto, não aplicável às redes ad hoc que são o foco deste artigo.

O DCF utiliza o protocolo CSMAVCA (Carrier-Sentse Multiple Access/Collision Avoidance) para controlar o acesso ao meio (Figura 1), pois em uma rede sem fio os terminais são capazes apenas de detectar a colisão na recepção, devido a grande diferença da potência entre o sinal transmitido e o sinal recebido, ocasionada pela atenuação do ar. Assim, torna-se necessária a utilização de um reconhecimento (ACK) para informar que o pacote foi recebido corretamente. Após escutar o meio vazio, o terminal deve aguardar um certo intervalo de tempo (IFS - Inter-Frame Space) antes de começar a transmissão. O valor deste intervalo de tempo é determinado pelo tipo de pacote a ser transmitido. Os pacotes de ACK utilizam um intervalo de tempo chamado de SIFS (Short Inter-Frame Space) e têm prioridade sobre os pacotes de dados, que usam o intervalo DIFS (Distributed Inter-Frame Space). Além disto, para evitar colisão, un ter- 
nuinal deve esperar, além do tempo DIFS, un tempo aleatótio (backoff). No caso de vários terminais tentaren transmitir ao mesmo tempo, aquele que tiver o menor tempo de backoff irá transmitir primeiro. Este tempo é calculado a partir de um fator que depende do número de vezes consecutivas de geração do backoff multiplicado por um número aleatório.

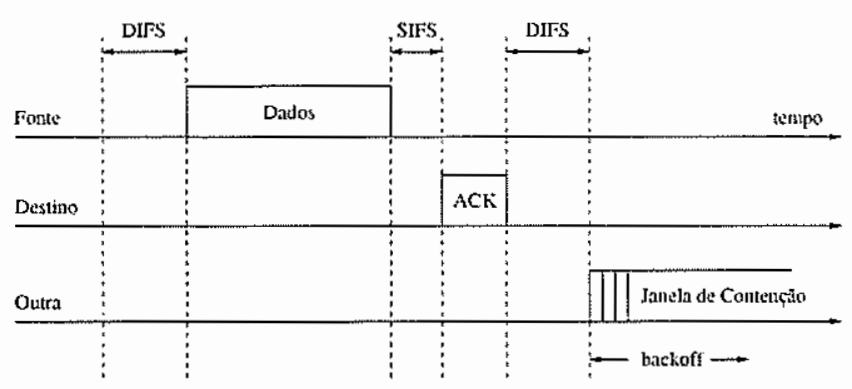

Figura 1. Esquema básico de acesso no DCF.

Com o objetivo de evitar o problema do terminal escondido foram definidos o quadro RTS (Request to Send) e o quadro CTS (Clear to Send), que armazenam informações referentes à duração das transmissões. Desta maneira, as estações devem enviar, antes de cada transmissão, um quadro RTS e esperar pela resposta da estação destino, que por sua vez deve enviar um quadro CTS, sinalizando que o nó fonte pode iniciar a transmissão, como mostrado na Figura 2. Todas as estaçōes que escutarem o RTS ou CTS devem atualizar o valor do seu vetor de alocação (NAV - Network Allocation Vector), que contém o tempo em que o canal estará ocupado. Este mecanismo acrescenta uma sobrecarga (overhead) ao DCF, diminuindo a sua eficiência. Por isso, foi proposto um tamanho mínimo de quadro, a partir do qual este mecanismo deve ser utilizado. Crow et al. [17] analisaram o efeito do RTS na vazão da rede e concluíram que o valor ideal para o tamanho mínimo de pacote é em tomo de 250 octetos, ou seja, todos os quadros menores que este valor não precisam ser precedidos de quadros RTS e CTS.

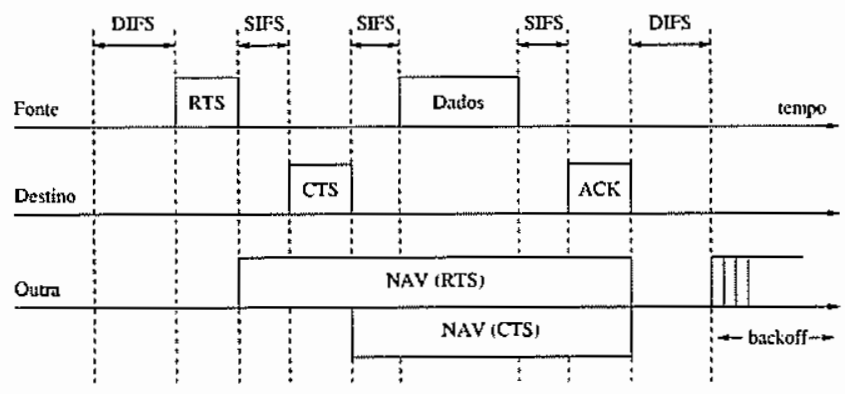

Figura 2. O mecanismo DCF com RTS e CTS.

Existem três técnicas para oferecer diferenciação de serviço em redes sem fio baseadas no IEEE 802.11. Estas técnicas consistem, basicamente, na variação de três parâmetros do mecanismo DCF para prover qualidade de serviço estatística ou determinística em redes ad hoc.

A primeira técnica consiste em alterar o valor do atraso aleatório (backoff). Esta técnica se baseia na variação da função que gera o backoff, alterando-se o fator multiplicativo ou o valor máximo da janela do backoff, de maneira que cada terminal possa ter uma função diferente de acordo com a qualidade de serviço requerida. As estaçôes com maior prioridade teriam un fator multiplicativo menor, ou uma janela de tempo menor, que as estaçōes com menor prioridade, proporcionando um menor tempo de espera no acesso ao meio.

A segunda técnica consiste na mudança do valor DIFS, que pode ser variado de acordo com a prioridade de cada estação, desta maneira, as estações com maior prioridade de acesso ao meio teriam um DIFS menor. Esta técnica também possibilita um menor tempo de espera no acesso ao meio.

A última técnica baseia-se na modificação do tamanho máximo do quadro a ser transnitido. Neste caso, as estações com maior prioridade poderiam transnutir quadros maiores que as demais estações. Esta técnica garante a diferenciação da qualidade de serviço ao permitir a transmissão de uma maior quantidade de informação a cada quadro, ao invés de fornecer prioridade no acesso ao meio, como as duas anteriores. Por este motivo, esta técnica não é adequada para transmissão de voz, pois o aumento do tamanho do quadro implica um aumento no atraso.

\section{AS SIMULAÇÕES}

Nesta seção são apresentadas as principais características da modelagem bem como detalhes referentes às simulaçōes com os seus respectivos resultados. As simulaçôes foram realizadas no simulador de redes ns-2 [18] e foram divididas em duas partes: uma referente à provisão de QoS e outra à mobilidade, sendo que na parte referente à mobilidade também foi avaliado o efeito da densidade de nós da rede. Em ambas, a taxa de transmissão na camada física é de $11 \mathrm{Mbps}$ e o protocolo de roteamento utilizado é o DSR (Dynamic Source Routing) [19] por ser um dos protocolos mais estudados na comunidade. Para todas as medidas, foram calculados intervalos de confiança de $90 \%$ relativos à média das amostras.

Com o objetivo de simular conversações telefônicas, as fontes de voz foram modeladas segundo uma cadeia de Markov de dois estados (on - off), representando momentos de atividade, nos quais o tráfego de voz gerado é modelado por uma fonte com taxa binária constante (CBR - Constant Bit Rate), e momentos de silêncio, nos quais nenhum tráfego de voz é gerado. O tempo de permanência em cada estado é representado por uma variável aleatória com distribuição exponencial de média 1,2 s para o estado ativo e 1,8 s para o estado de silêncio $[20,21]$. A taxa de transmissão no período ativo é de $64 \mathrm{kbps}$, simulando uma voz PCM (Pulse Code Modulation), com pacotes de 160 octetos [12].

Para simular o congestionamento da rede foi introduzido un tráfego de fundo modelado a partir de 5 fontes CBR transmitindo pacotes de 500 octetos a taxas de $200 \mathrm{kbps}$ e $250 \mathrm{kbps}$, referentes à média carga e à alta carga na rede, respectivamente. Com objetivo de minimizar o tamanho do intervalo de confiança foi escolhido um tempo de simulação de $400 \mathrm{~s}$. O tempo de início de transmissão de cada fonte é aleatório, uniformemente distribuído no intervalo de $1 \mathrm{~s} \mathrm{a}$ $11 \mathrm{~s}$, assim, impedindo que todas as fontes comecem a transmitir sinultaneamente.

Cada pacote de voz possui um tempo de vida de $250 \mathrm{~ms}$, assin, cada pacote que chega com un atraso maior que este 
limite é descartado e considerado como uma perda. Os tempos de codificação, de geração de pacotes e de espera na fila (buffer) do receptor foram desprezados. Foi definido como parâmetro de qualidade de serviço um limite máximo de 5\% de perdas de quadros em cada fluxo de voz [12]. Desta forma, variando-se o número de estações, pôde-se chegar a um número ótimo de estações transmitindo voz em uma rede ad hoc baseada no padrão IEEE 802.11.

\subsection{RESULTADOS RELATIVOS À PROVISÃo DE QOS}

Nesta parte das simulações foi utilizada a técnica de variação do tamanho da janela de contenção da camada MAC do IEEE 802.11 a fim de dar prioridade ao tráfego de voz em relação ao tráfego de fundo. Esta técnica apresenta a vantagem de minimizar o número de colisões devido à escolha de tempos iguais de backoff por duas ou mais estações, além de prover a diferenciação de serviço. O cenário de simulação corresponde a uma rede ad hoc de comunicação direta. Procura-se obter resultados de QoS sem interferência dos problemas ocasionados pelo roteamento em redes ad hoc de múltiplos saltos. Assim o cenário consiste em uma área de $150 \mathrm{~m} \times 150 \mathrm{~m}$ com a presença de 30 nós fixos com raio de transmissão de $250 \mathrm{~m}$, resultando em um cenário onde todos os nós estão diretamente alcançáveis. Nas simulações foram utilizados dois níveis de prioridade. Na prioridade baixa a relação entre o tamanho das janelas de contenção das fontes de voz e das fontes de dados é de $1 / 2$, enquanto que na prioridade média esta relação é de $1 / 3$.

Primeiramente foram realizadas simulações com a finalidade de verificar a influência da carga da rede no tempo de acesso ao meio. As Figuras 3 e 4 mostram como o aumento do tráfego influencia a capacidade de transmissão da rede devido ao tempo de acesso ao meio, visto que todos os nós se comunicam diretamente e como os nós estão fixos, a descoberta de rotas se dá apenas no início da simulação e quando expira a validade das rotas. Os resultados revelam que com um aumento de $25 \%$ da carga (de 1 Mbps para $1,25 \mathrm{Mbps})$ percebe-se uma queda na capacidade da rede, comprovando que o aumento da carga da rede afeta a transmissāo de voz em tempo-real.

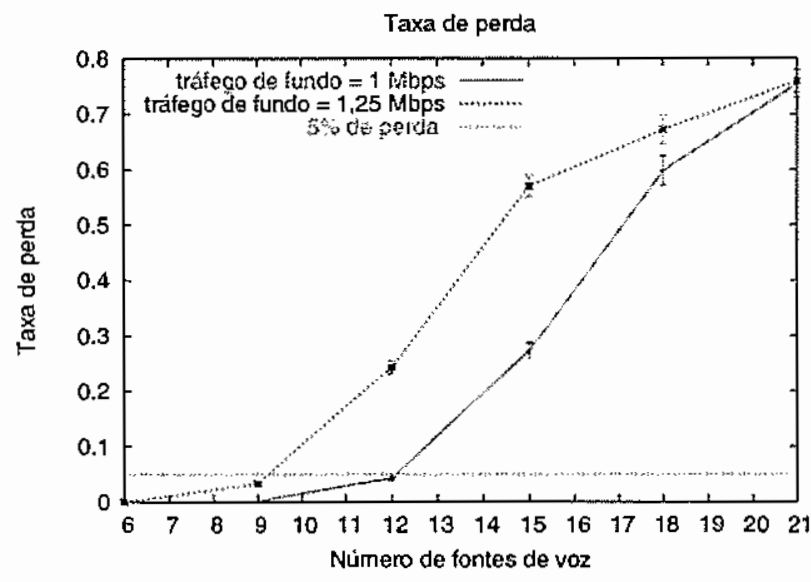

Figura 3. Influência da carga da rede.

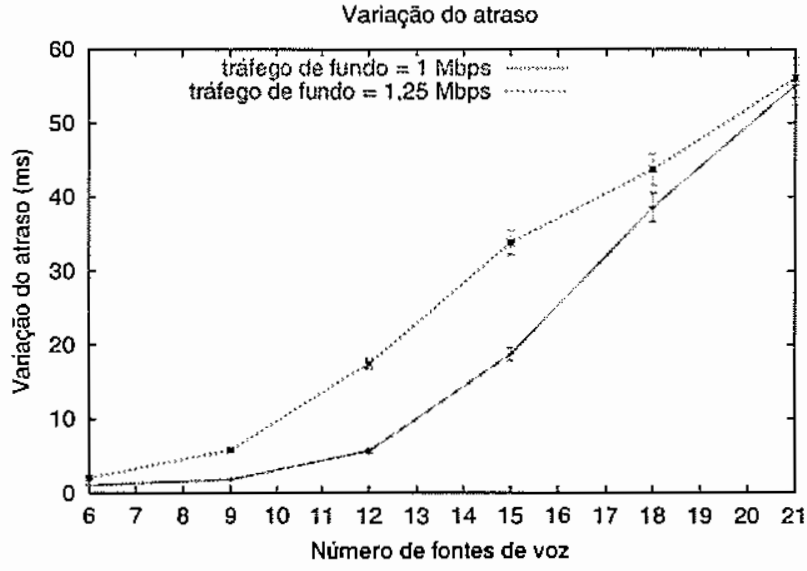

Figura 4. Influência da carga da rede.

A Figura 5 revela a sensibilidade da taxa de perda e da variação do atraso em relação ao aumento da carga na rede. A curva de sensibilidade da taxa de perda é oriunda da divisão dos valores da curva referente à alta carga pela curva referente à média carga, na Figura 3. O mesmo procedimento foi executado para extrair a curva de sensibilidade da variação do atraso, ou seja, esta curva é o resultado da divisão entre as duas curvas da Figura 4. Percebe-se que a taxa de perda apresenta uma variação grande para um pequeno número de fontes de voz e conforme este número aumenta a variação na taxa de perda diminui. Isto porque ambas as curvas se aproximam do valor limite de taxa de perda (valor 1), ou seja, a razão entre elas tende a 1 . A variação do atraso se mostrou menos sensível à variação da carga para um pequeno número de fontes de voz. O aumento do número de fontes de voz faz a curva da variação do atraso ultrapassar levemente a curva da taxa de perda e ficar perto de 1 também, como mostra a Figura 6 (zoom da Figura 5), pois com um alto mível de perdas são poucos os pacotes que realmente chegam ao receptor, não fazendo tanta diferença o tráfego de fundo.

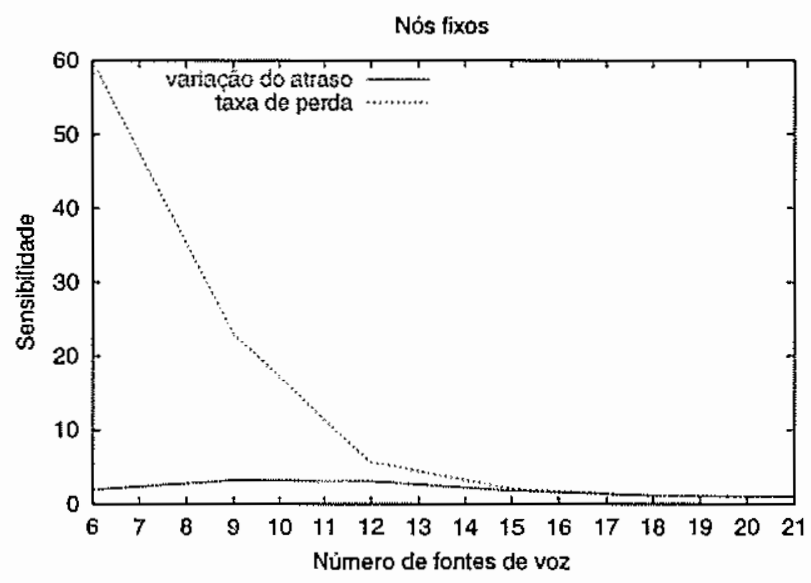

Figura 5. Sensibilidade ao aumento da carga da rede.

Utilizando-se a técnica de alteração do tamanho máximo da janela de backoff pôde-se avaliar o efeito da provisão de QoS na transmissão de voz. A partir da Figura 7, verificase que em uma rede com média carga, a baixa prioridade, 


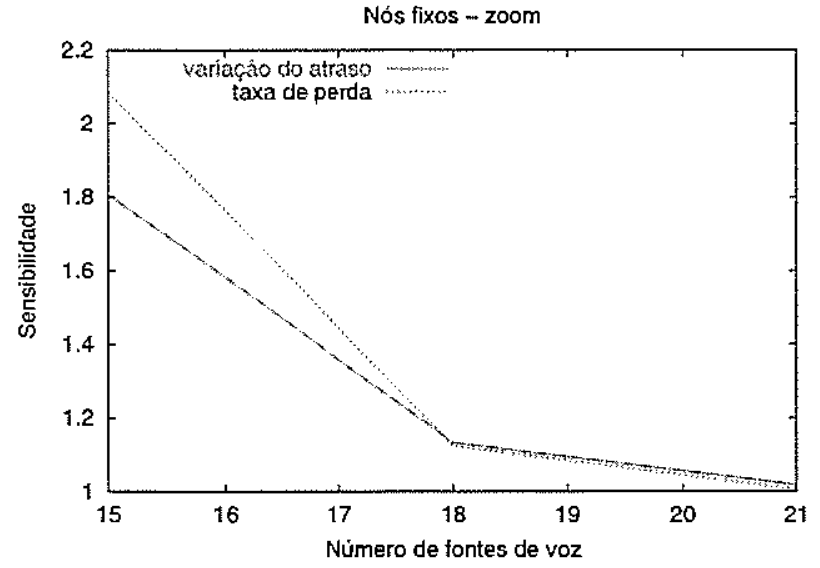

Figura 6. Sensibilidade ao aumento da carga da rede.

apesar de apresentar uma melhora não proporcionou un aumento no número de fontes transmitindo voz, enquanto que a prioridade mais alta obteve um aumento de uma fonte de voz. Isto demonstra que a variação da janela de contenção possibilita aumentar a capacidade de transmissão de voz, embora este aumento não tenha sido tão significativo neste cenário. Constatou-se também, que esta técnica proporcionou um nível maior de diferenciação quando a rede foi submetida a uma carga maior (Figura 8).

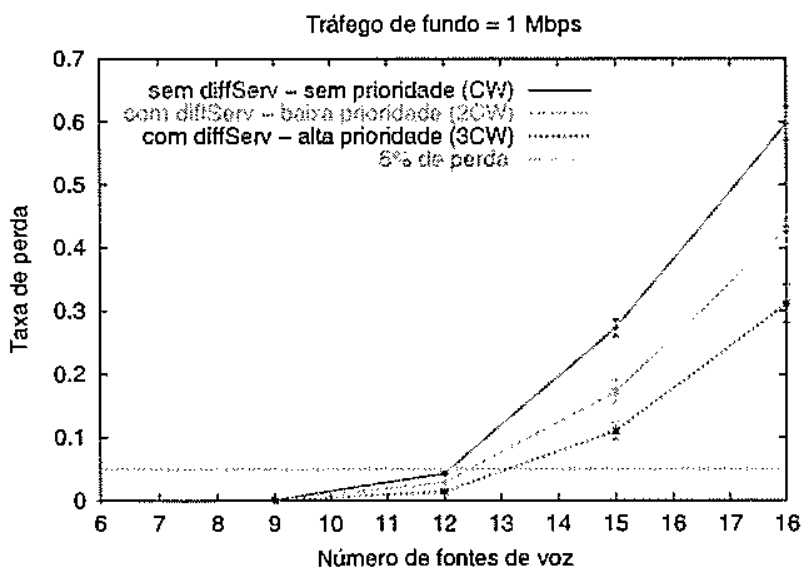

Figura 7. Efeito da provisão de QoS na taxa de perda.

Pelas Figuras 9 e 10, observa-se a relação entre a variação da janela de contenção, para a provisão de QoS, e a variação do atraso. Os resultados mostram que esta técnica proporcionou uma diminuição do valor da variação do atraso.

A Figura 11 apresenta a função de probabilidade acumulada (PMF - Probability Mass Function) do número de perdas consecutivas. As curvas apresentam as perdas consecutivas referentes a doze fontes a média carga e nove fontes a alta carga, que representam os valores máximos de capacidade de transmissão de voz obtidos na Figura 3. Ambas as curvas apresentam comportamento similar. Como se trata de um cenário de comunicação direta e, portanto, não há quebra de enlaces nem espera por rotas, o principal responsável pelo aumento da taxa de perda acaba sendo o atraso de acesso ao meio. O atraso de acesso ao meio é influenciado pela carga 190

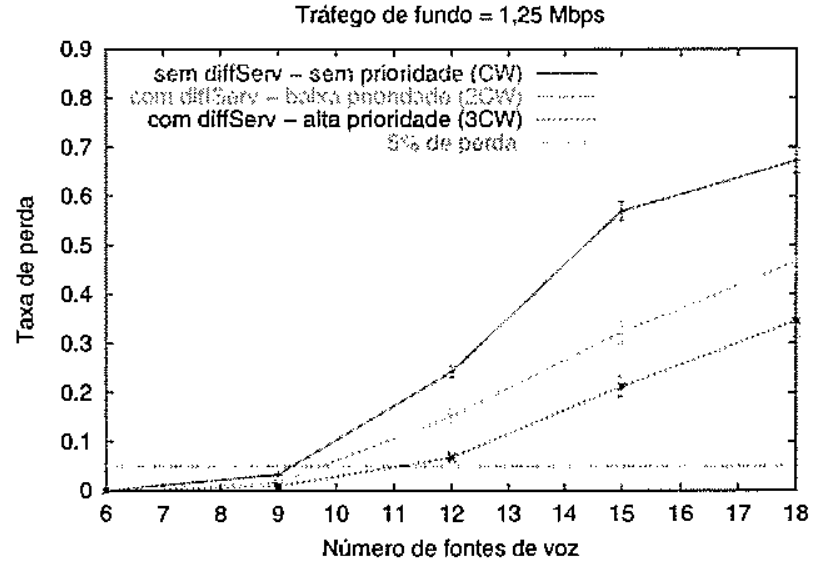

Figura 8. Efeito da provisão de QoS na taxa de perda.

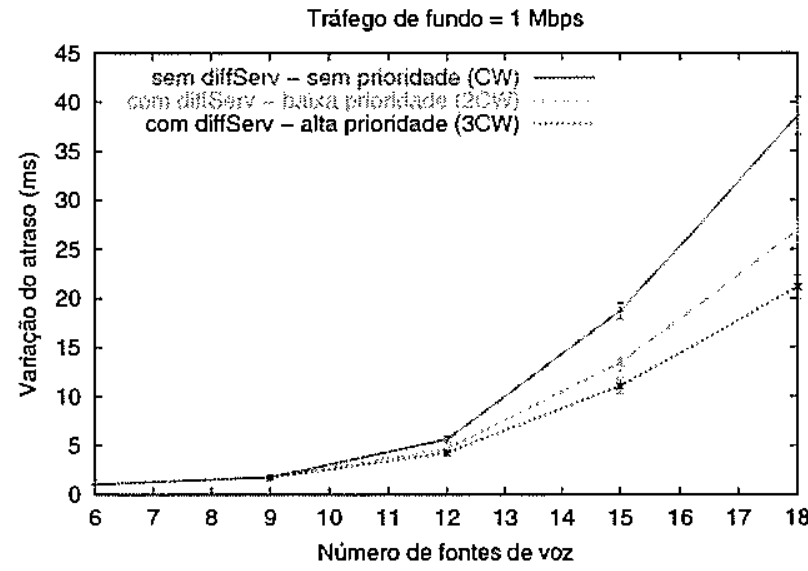

Figura 9. Efeito da provisão de QoS na variação do atraso.

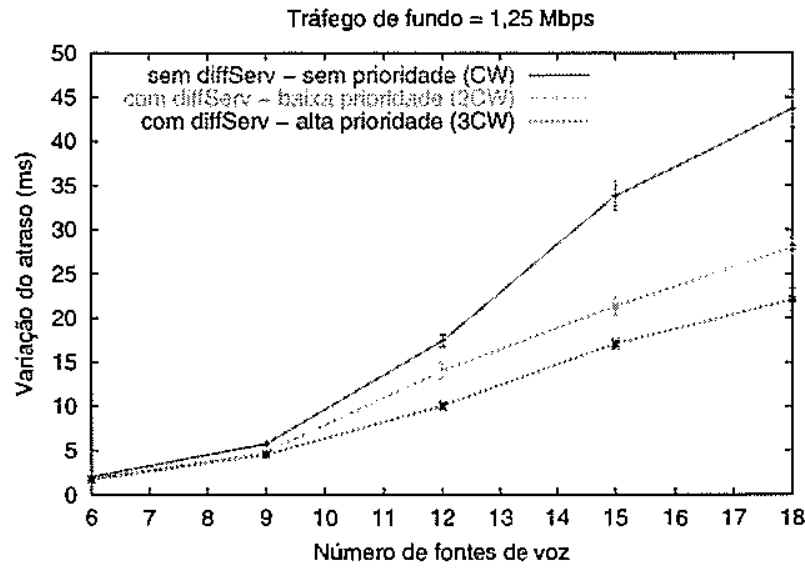

Figura 10. Efeito da provisão de QoS na variação do atraso.

da rede e pelo número de estações transmitindo. Somando-se o tráfego de voz ao tráfego de fundo, de ambos os cenários, nota-se que o cenário de média carga possui um tráfego total ligeiramente maior, no entanto, o cenário de baixa carga possui mais estações transmitindo. Desta maneira, esta diferenç a toma os tempos de acesso ao meio neste dois pontos específicos (12 fontes/baixa carga e 9 fontes/média carga) praticamente equivalentes. Deve-se ressaltar também, que para 0 
cenário de comumicação direta as perdas em rajadas não passaram de 100 perdas consecutivas.

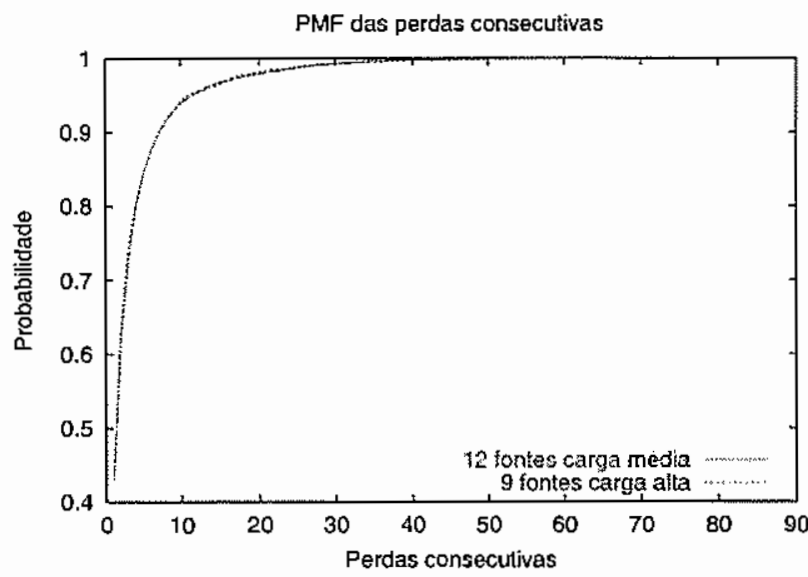

Figura 11. Efeito da carga na PMF da perdas consecutivas.

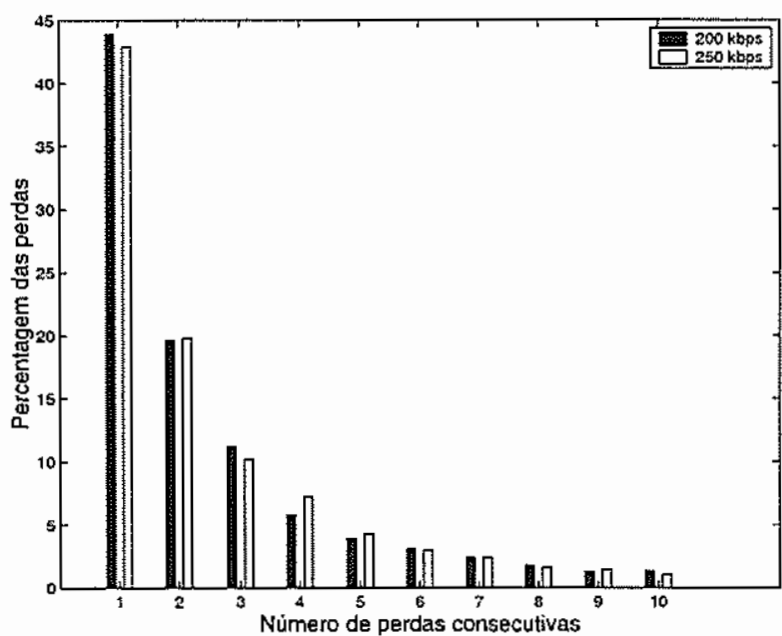

Figura 12. Efeito da carga nas perdas consecutivas.

A Figura 12 apresenta a função densidade de probabilidade (PDF - Probability Density Function) condicional do número de perdas consecutivas, condicionada em uma perda, como mostra a fórmula:

$$
P\left(k \mid 1^{a}\right)=\frac{P(k) \bigcap P\left(1^{a}\right)}{P\left(1^{a}\right)}, k \in \mathbb{N} .
$$

Isto é, dada a ocorência de uma perda (a primeira perda) qual a probabilidade de acontecerem $k$ perdas consecutivas. A Figura 12 confirma a similaridade do comportamento das perdas em rajadas. Além disso, percebe-se que dada a ocorrência da primeira perda a probabilidade de ocorrer até 4 perdas consecutivas é maior que $80 \%$, o que representa a grande maioria das perdas em rajada.

\subsection{RESULTADOS RELATIVOS À MOBILI- DADE}

Em seguida foram realizadas simulações para avaliar o efeito da mobilidade na capacidade de transmissão de voz em redes ad hoc de múltiplos saltos. É importante observar que o cenário de múltiplos saltos com mobilidade é ben mais adverso que o cenário de comunicação direta para se oferecer qualidade de serviço. No cenário de múltiplos saltos, acrescentam-se aos problemas de acesso, a possível falta de conectividade, a descoberta dinâmica de rota e a transferência em saltos. Os cenários utilizados nas simulações possuem 40 nós com raio de transmissão de $250 \mathrm{~m}$ em uma área retangular de $800 \mathrm{~m} \times 600 \mathrm{~m}$. Desta forma, o número máximo de enlaces que um pacote deve perconer para chegar ao nó destino, pelo melhor caminlıo, é igual a quatro e com uma densidade de $1 / 12000 \mathrm{~m}^{2}$, ou seja, um nó a cada área de $120 \mathrm{~m}$ $\times 100 \mathrm{~m}$, o que proporciona uma grande conectividade.

O pacote do ns-2 disponibiliza um gerador de cenários (setdest), que utiliza o modelo de mobilidade randon way point. Por isso não foi preciso criar um novo modelo de movimentação. Neste modelo, cada nó deve escolher aleatoriamente um destino, dentro da área de simulação, para o qual ele deve se dirigir a uma velocidade $v$, uniformemente distribuída entre o intervalo de zero a $v_{\text {max. }}$. Após chegar ao destino, o nó deve aguardar por um determinado intervalo de tempo (pausa) previamente definido. Após o tempo de pausa o nó escolhe um novo destino e uma nova velocidade, com a qual ele se movimentará.

Foram simulados dois méveis de mobilidade: baixa e média, com tempo de pausa igual a zero e com velocidade média de $1 \mathrm{~m} / \mathrm{s}$ e $4 \mathrm{~m} / \mathrm{s}$, respectivamente. Foi feita uma pequena modificação do modelo random way point a fim de suavizar a mudança de velocidade. Assim, a velocidade de cada nó $(v)$ está distribuída uniformemente no seguinte intervalo: $0,8 v_{m} \leq v \leq 1,2 v_{m}$, onde $v_{m}$ representa a velocidade média. Para cada mível de mobilidade simulou-se o comportamento da rede com carga zero e com baixa carga. Não foram realizadas simulações com carga alta, devido à baixa capacidade de transmissäo das redes de múltiplos saltos.

Nestes cenários específicos, o tráfego de fundo foi modelado a partir de 20 fontes CBR transmitindo a uma taxa de $16 \mathrm{kbps}$ a fim de mimimizar a variância dos resultados. Cada resultado é uma média de diversas medidas com um intervalo de confiança de $90 \%$. As medidas são referentes a diferentes rodadas de simulação, sendo que para cada rodada são gerados diferentes cenários respeitando as configuraçōes previamente estabelecidas.

As Figuras 13 e 14 mostram a influência da mobilidade na capacidade da rede em relação ao número de fontes de voz. Conforme o número de fontes aumenta, cresce a taxa de perda. Em uma rede senı carga é possível ter 10 fontes de voz para uma baixa mobilidade e apenas 4 para uma média mobilidade (Figura I3), enquanto que uma rede com baixa carga suporta 5 fontes de voz para um nível de mobilidade baixo (Figura 14), levando-se em consideração a taxa máxima de perda de pacotes de voz de $5 \%$. Assim, pode-se perceber que o aumento da mobilidade prejudica a capacidade da rede, chegando a $60 \%$ do nível baixo de mobilidade para o nível inédio. Os resuItados referentes ao mivel de mobilidade média com baixa carga na rede não são apresentados, porque nesta configuração não é possível obter fontes transmitindo voz com uma taxa de perda inferior a $5 \%$.

As Figuras 15 e 16 permitem avaliar o impacto da mo- 
bilidade na variação do atraso, deixando mais evidente a degradação da capacidade da rede a partir do aumento da mobilidade e do aumento da carga na rede.

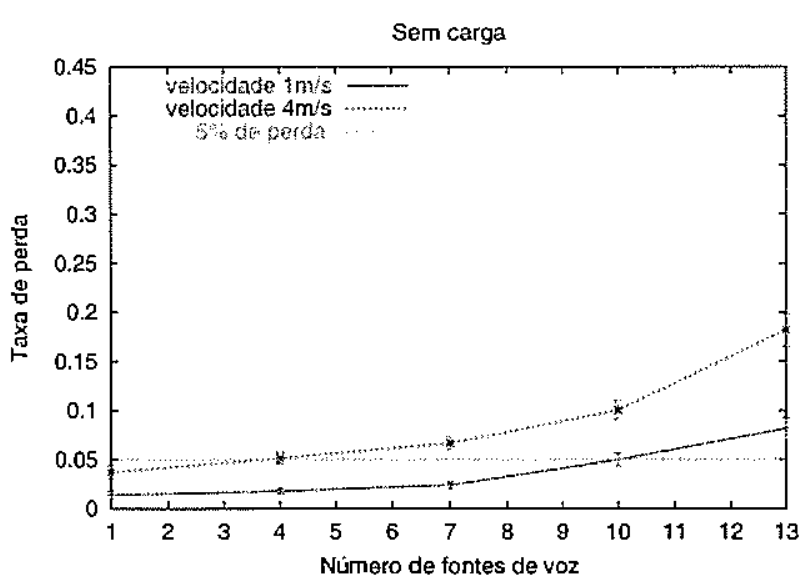

Figura 13. Efeito da mobilidade na taxa de perda.

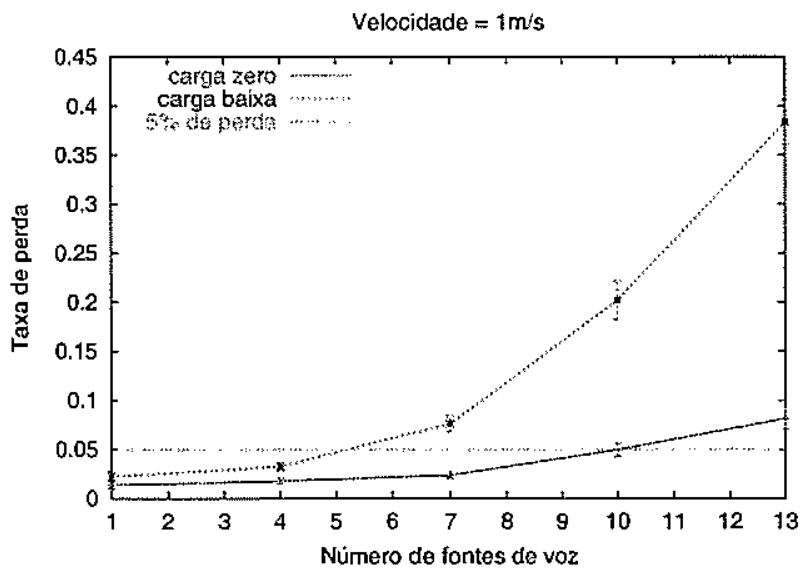

Figura 14. Efeito da mobilidade na taxa de perda.

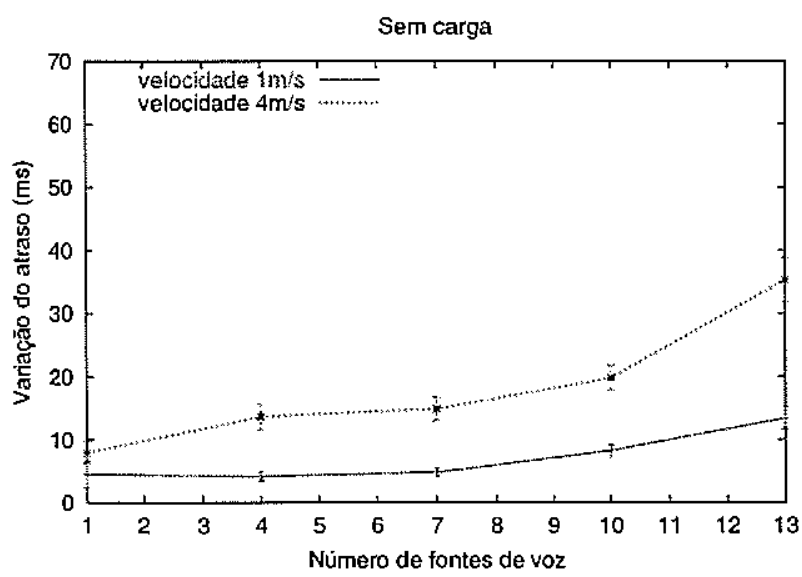

Figura 15. Efeito da mobilidade na variação do atraso.

A Figura 17 apresenta a PMF das perdas consecutivas no cenário de baixa mobilidade e sem carga. A capacidade de transmissão de voz deste cenário é de dez fontes, enquanto 192

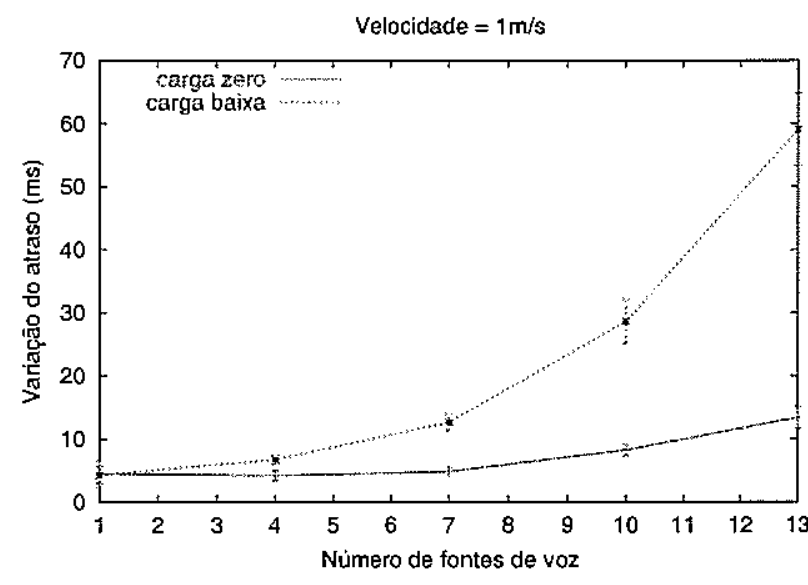

Figura 16. Efeito da mobilidade na variação do atraso.

que a taxa de perda para sete fontes e treze fontes é aproximadamente de $2,4 \%$ e $8,1 \%$, respectivamente (Figura 13 ). A Figura 17 mostra que quanto maior o número de fontes de voz transmitindo, mais rápido a curva se aproxima do valor um. Isto significa que quando a rede está com pouca carga, as perdas em grandes rajadas tendem a ser mais representativas. 1sto acontece porque neste tipo de cenánio, ocorren quebras de enlace devido a mudanças na topologia, podendo causar perdas de pacotes em grandes rajadas. É importante mencionar que apesar da figura mostrar apenas valores de rajadas até 250 pacotes, este valor pode clıegar até 2.000 pacotes consecutivos. Este número é bem superior aos 100 pacotes do cenário de comunicação de direta, evidenciando novamente, o impacto da quebra de enlaces.

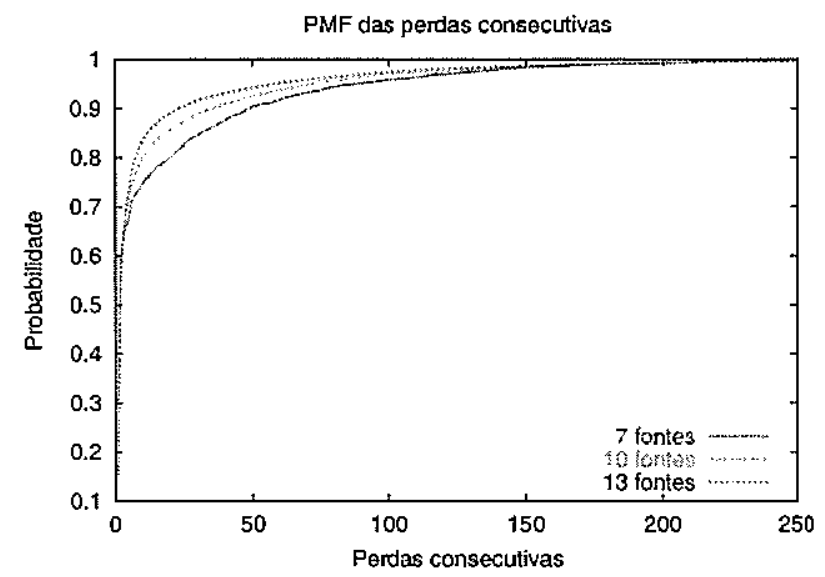

Figura 17. Perdas consecutivas - $1 \mathrm{~m} / \mathrm{s}$ e sem carga.

A Figura 18 mostra a PDF condicional dada a ocorrência da primeira perda. Pode-se observar que as ocorrências de uma única perda e duas perdas consecutivas representam a maior parte das perdas em rajada.

A Figura 19 deixa mais clara a diferença entre as curvas da Figura 17. Nota-se que até onze perdas consecutivas representa $80 \%$ das perdas en rajada no limite da capacidade deste cenário (dez fontes de voz), enquanto que para sete fontes de voz este vaIor é quase o dobro, apesar de apresentar uma taxa de perda $(2,4 \%)$ inferior ao cenário de dez fontes de voz $(5 \%)$. 


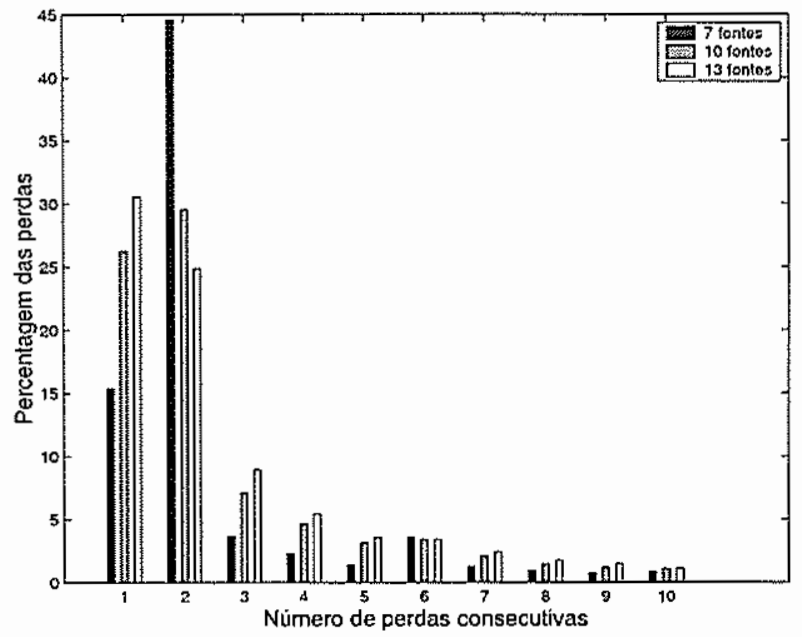

Figura 18. Perdas consecutivas - $1 \mathrm{~m} / \mathrm{s}$ e sem carga.

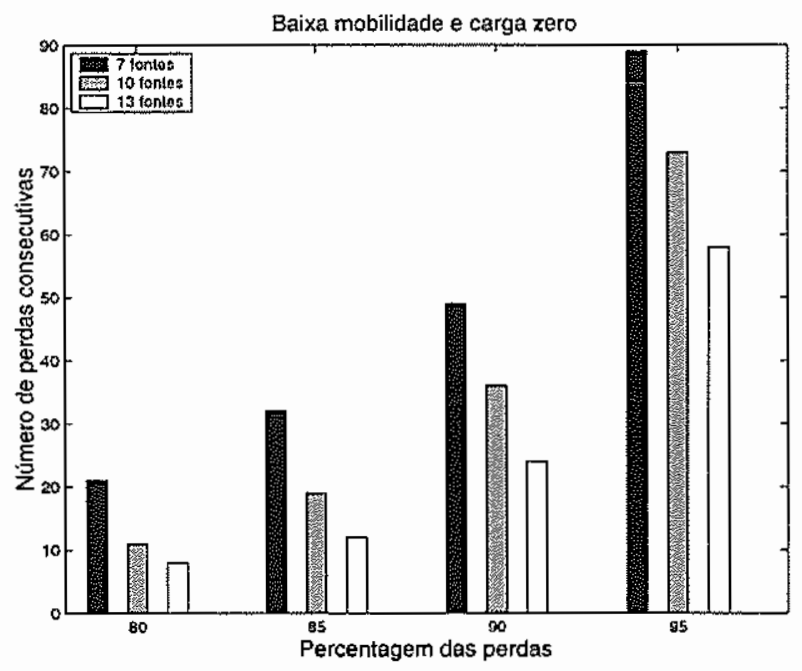

Figura 19. Perdas consecutivas - $1 \mathrm{~m} / \mathrm{s}$ e sem carga.

A Figura 20 apresenta a PMF das perdas consecutivas para cenários de baixa e média mobilidade. Ambas as curvas correspondem ao limite máximo da capacidade de transmissão de voz cada cenário (Figura 13). O cenário de média mobilidade possui menos da metade da carga da rede que o cenário de baixa mobilidade e apresenta a mesma taxa de perda, no entanto, pode-se perceber uma pequena diferença no comportamento das perdas em rajada. Esta diferença fica ainda mais evidente na Figura 22. Isto acontece, pois o aumento da mobilidade provoca mudanças de topologia que estão diretamente relacionadas com a quebra de enlaces.

A probabilidade condicional, mostrada na Figura 21, revela que apesar das quebras de enlaces provocarem perdas em grandes rajadas, dado que aconteceu a primeira perda, a probabilidade que esta rajada contenha menos de 3 pacotes é ainda bem alta.

Outro aspecto importante a ser analisado é a causa das perdas dos pacotes em relação à mobilidade e à carga da rede. Os pacotes perdidos foram separados em dois grupos, de acordo com o motivo que originou a perda. O primeiro grupo referese a todos os pacotes descartados pelo receptor devido à expiração do tempo de vida do pacote, previamente definido em

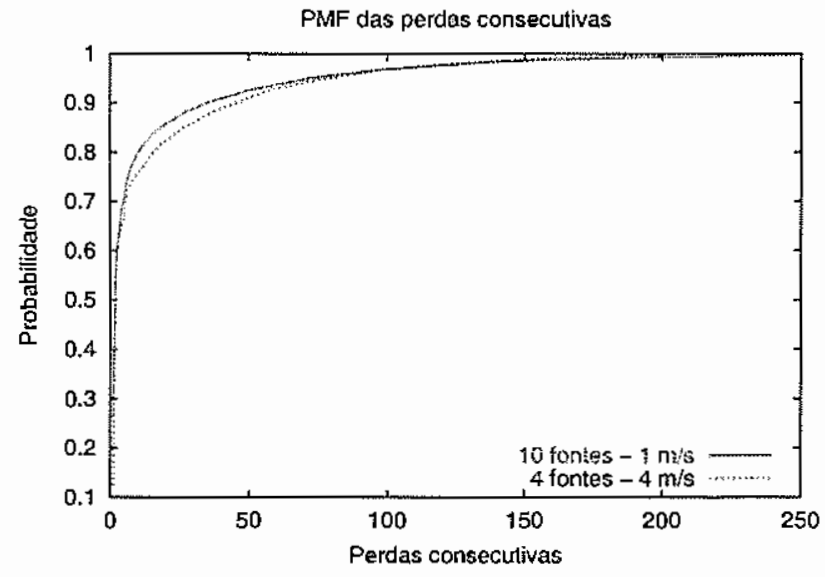

Figura 20. Efeito da mobilidade nas perdas consecutivas.

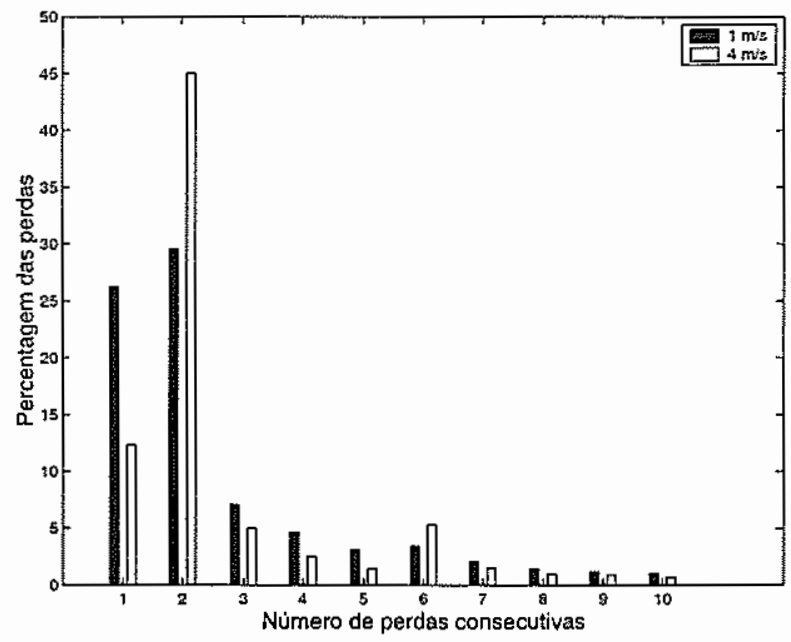

Figura 21. Efeito da mobilidade nas perdas consecutivas.

$250 \mathrm{~ms}$. O outro grupo refere-se a todos os outros pacotes que foram perdidos por outros motivos, tais como, a colisão e o transbordo da fila da camada MAC. Estes grupos são denominados "tempo de vida"e "outros", respectivamente.

As Tabelas 2 e 3 apresentam a percentagem de perda referente a estes dois grupos em relação à média do total de pacotes perdidos, ao variar a mobilidade e a carga da rede. Verifica-se que ao aumentar a carga da rede, a percentagem de pacotes descartados devido à expiração do tempo de vida manteve-se quase constante, apesar do aumento da média do total de perdas. Isto mostra que o aumento da carga provoca um aumento no tempo de acesso ao meio, causando não apenas um aumento do atraso do pacote, mas também un aumento do número de pacotes perdidos devido a transbordo das filas da camada MAC. Por outro lado, quando se aumentou a mobilidade a percentagem de pacotes perdidos por outros motivos aumentou. Isto ocorre porque o aumento da mobilidade provoca uma diminuição da taxa de entrega de pacotes do protocolo de roteamento, como mostraram Royer et al. [22].

As Figuras 23 e 24 a seguir mostram a variação dos resultados em relação à variação do tráfego de fundo e do nível de mobilidade, isto é, a sensibilidade da variação do atraso e da 


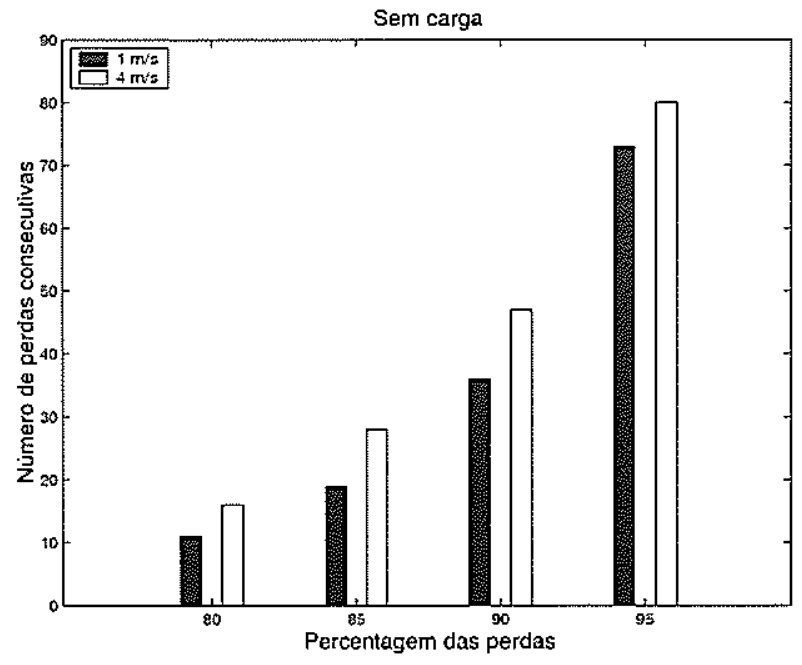

Figura 22. Efeito da mobilidade nas perdas consecutivas.

Tabela 2. Causa das perdas com velocidade igual a $1 \mathrm{~m} / \mathrm{s}$.

\begin{tabular}{|c|c|c|c|c|}
\cline { 2 - 5 } \multicolumn{1}{c|}{} & \multicolumn{4}{c|}{ Causa de perdas } \\
\hline Carga & Tempo (\%) & Total & Outros (\%) & Total \\
\hline zero & 69,14 & $3.315,3$ & 30,86 & 1.270 \\
\hline baixa & 68,43 & $14.434,3$ & 31,57 & $8.614,1$ \\
\hline
\end{tabular}

Tabela 3. Causa das perdas com carga zero.

\begin{tabular}{|c|c|c|c|c|}
\cline { 2 - 5 } \multicolumn{1}{c|}{} & \multicolumn{4}{c|}{ Causa de perdas } \\
\hline Vel. & Tempo (\%) & Total & Outros (\%) & Total \\
\hline $1 \mathrm{~m} / \mathrm{s}$ & 69,14 & $3.315,3$ & 30,86 & 1.270 \\
\hline $4 \mathrm{~m} / \mathrm{s}$ & 45,64 & $3.095,4$ & 54,36 & $3.638,5$ \\
\hline
\end{tabular}

taxa de perda em relação às variaçōes das condições da rede. Desta forma, a partir da divisão dos valores das curvas das Figuras 13 e 14 obteve-se a sensibilidade da taxa de perda e a partir da divisão dos valores das curvas das Figuras 15 e 16 obteve-se a sensibilidade da variação do atraso. Nota-se, que a variação do atraso é mais sensível às variações na carga da rede que a taxa de perda, pois apresentou maior variação em relação à mudança deste parâmetro. Por outro lado, a taxa de perda mostrou-se mais sensível à variação da mobilidade que à variação do atraso, exceto pelo primeiro ponto, onde existe apenas uma fonte de voz transmitindo. Isto mostra que a taxa de perda não sofre um grande impacto da mobilidade em uma rede com baixa utilização.

A densidade de nós afeta a conectividade da rede que está diretamente relacionada à capacidade de transmissão dos nós. Para analisar o efeito da variação da densidade de nós na transmissão de voz foram gerados outros cenários variando a área de simulação e mantendo-se o número de nós constante igual a 40 . Desta forma, foram realizadas simulações com três áreas diferentes, representando três densidades diferentes. Uma primeira área de $600 \mathrm{~m} \times 600 \mathrm{~m}$ (área menor) representa uma densidade de 1 nó por $9.000 \mathrm{~m}^{2}$. A segunda área simulada é de $800 \mathrm{~m} \times 600 \mathrm{~m}$ (área média), a mesma área utilizada no restante do artigo, representando uma densidade de 1 nó por $12.000 \mathrm{~m}^{2}$. A última área simulada representa uma densidade de 1 nó por $15.000 \mathrm{~m}^{2}$ com uma 194

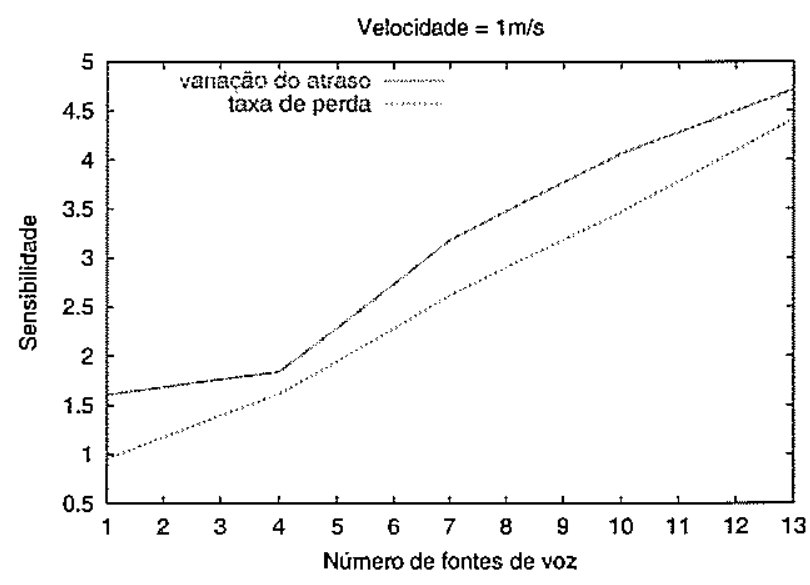

Figura 23. Sensibilidade em relação às condições da rede.

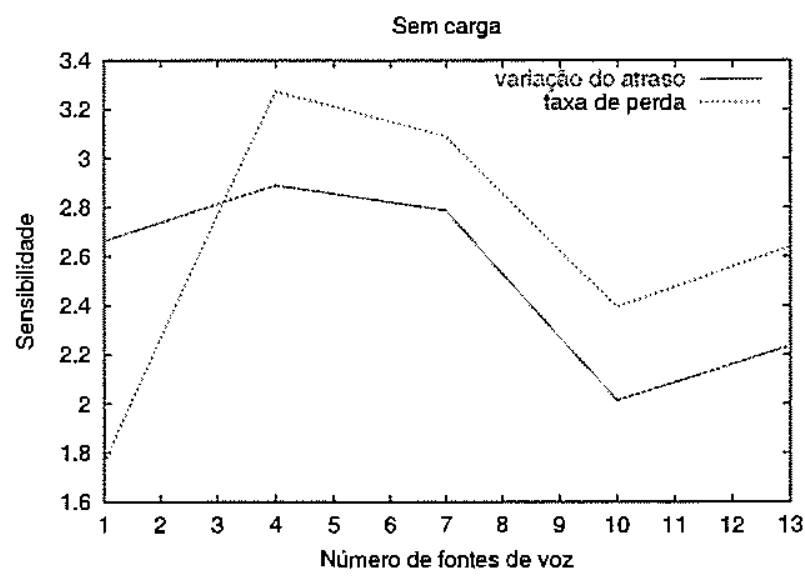

Figura 24. Sensibilidade em relação às condições da rede.

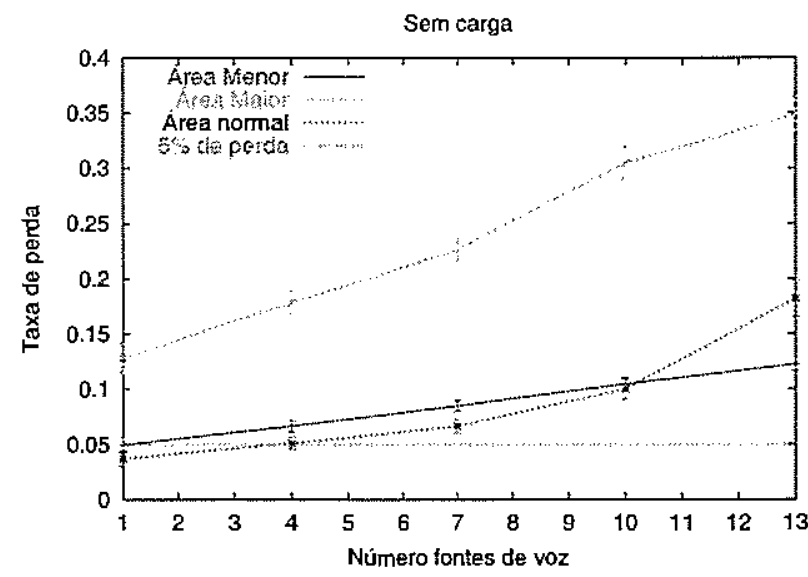

Figura 25. Efeito da densidade de nós da rede

área de $1.200 \mathrm{~m} \times 500 \mathrm{~m}$ (área maior). Os resultados podem ser observados pelas Figuras 25 e 26 . Pode-se perceber que tanto a taxa de perda quanto a variação do atraso apresentam um comportamento semelhante. A área maior apresentou um pior desempenho devido à baixa densidade de nós na rede, acarretando uma maior probabilidade de quebra de enlaces e a falta de conectividade. A área menor, onde há uma maior densidade de nós, obteve resultados ligeiramente piores que a área média, pois quanto maior a densidade de nós, maior é a disputa pelo meio. No entanto, percebe-se que conforme 


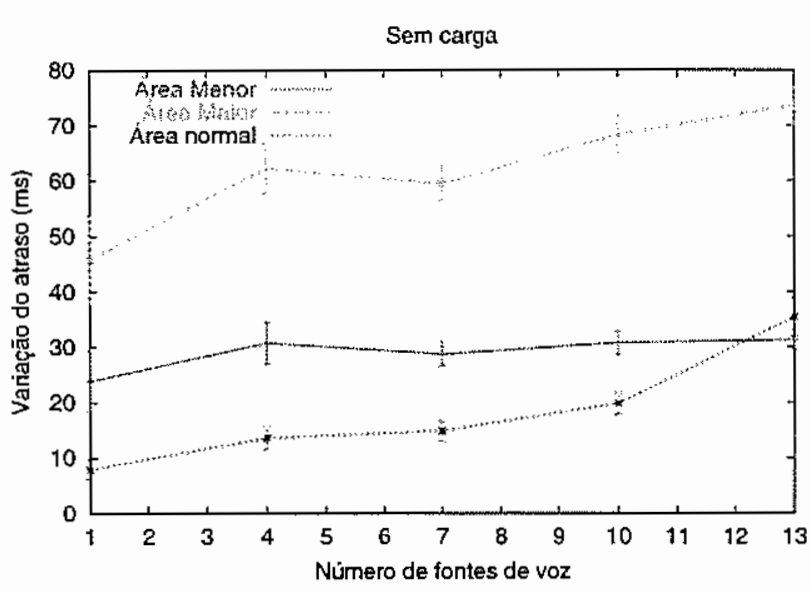

Figura 26. Efeito da densidade de nós da rede

se aumenta o número de fontes de voz, a capacidade da rede, na área média, vai se degradando até atingir a curva da área menor. Isto ocorre porque em uma área maior a probabilidade de acontecerem quebras de enlace aumenta e este efeito é agravado pelo aumento do número de fontes voz.

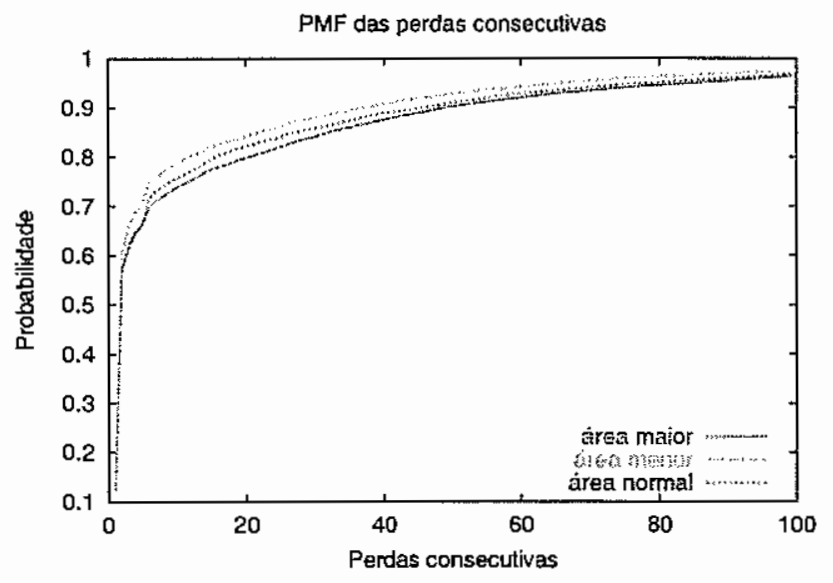

Figura 27. Efeito da densidade de nós nas perdas consecutivas.

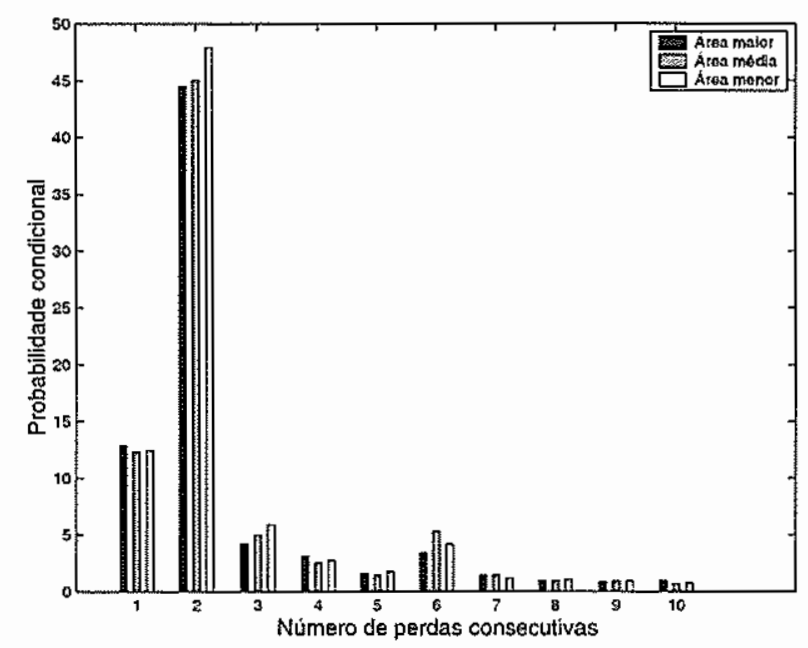

Figura 28. Efeito da densidade de nós nas perdas consecutivas.

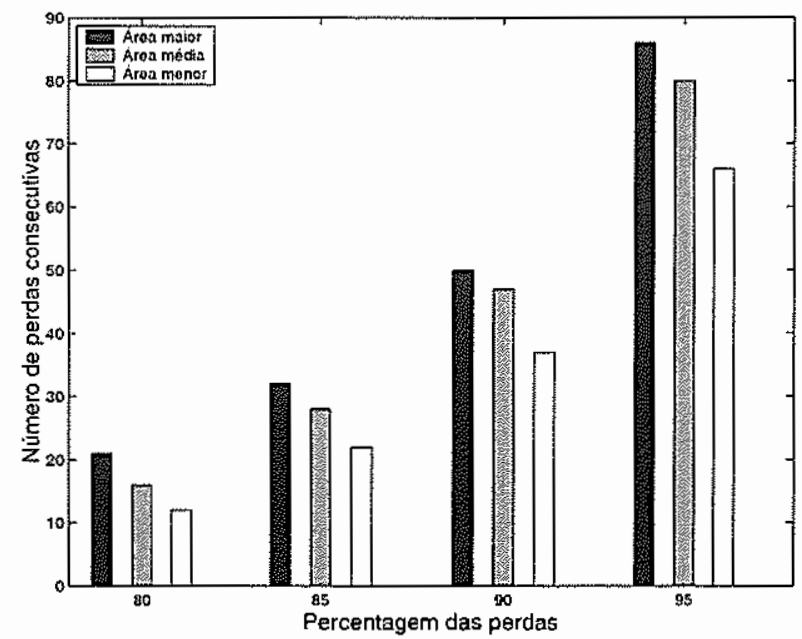

Figura 29. Efeito da densidade de nós nas perdas consecutivas.

As Figuras 27 e 29 mostram o comportamento das perdas consecutivas mediante a variação da densidade de nós da rede. O aumento da densidade de nós diminui as perdas em rajada, entretanto, a Figura 28 mostra que para rajadas pequenas o comportamento das perdas consecutivas é bastante semelhante nos três cenários simulados.

\section{CONCLUSÕES}

O principal objetivo deste trabalho foi analisar a capacidade de transmissão de voz em tempo-real em redes ad hoc. A análise abrange as redes ad hoc de comunicação direta e de múltiplos saltos. Para o cenário de comunicação direta foi realizada uma sequiência de simulações e avaliadas as infuências da carga da rede e da provisão de QoS no tráfego de voz. Uma outra seqüência de simulações mostrou as influências da carga da rede, da mobilidade e da densidade de nós da rede em cenários de múltiplos saltos. Em ambos os cenários, foram identificados os motivos que levaram a perda de pacotes. Para prover qualidade de serviço, foi utilizada uma técmica de diferenciação de serviço na subcamada MAC, baseada na variação da janela de contenção do mecanismo de acesso ao meio DCF do padrão IEEE 802.11. Foi defimido como parâmetro de qualidade de serviço um atraso máximo de pacote de voz de $250 \mathrm{~ms}$ e uma taxa de perda máxima de 5\%. A partir destes parâmetros, foi obtida a capacidade de transmissão de voz em cada um dos cenários.

Os resultados mostram que mesmo em cenários bastante adversos onde a rede está carregada e os nós se movem constantemente é viável a comnunicação de voz sem perda de interatividade. Entretanto, comprova-se que o aumento, tanto da mobilidade quanto da carga da rede, implica a degradação da capacidade de transmissão de voz. O aumento da carga da rede afeta diretamente o tempo de acesso ao meio, aumentando, por consequiência, o descarte de pacotes devido à expiração do tempo de vida, enquanto a variação da mobilidade provoca perdas de pacotes devido a espera por rota. A diminuição da densidade de nós da rede teve um efeito negativo na capacidade de transmissão da rede, devido ao aumento da probabilidade de quebras de enlace e o aumento do número de saltos necessários para cobrir a maior distância en- 
tre os nós. Este último efeito foi ocasionado pela forma que se diminuiu a densidade pois aumentou-se a área ao invés de reduzir o número de nós.

A taxa de perda se mostrou, para um número pequeno de nós, mais sensível que a variação do atraso no cenário estático, onde todos os nós se comunicavam diretamente. Já no cenário dinâmico, a variação do atraso (jitter) se mostrou mais sensível à carga e menos sensível à mobilidade.

A análise das perdas em rajada revelou que as perdas de apenas um pacote e de dois pacotes consecutivos representam a maior parte das perdas em rajadas tanto nos cenários de comunicação direta quanto nos de múltiplos saltos. A partir dos resultados, pôde-se verificar que nas redes de múltiplos saltos, as perdas em grandes rajadas significam uma pequena parte das perdas consecutivas, porém, em relação ao total de perdas, elas representan a grande parte.

Outro resultado importante se refere à questão da complexidade das redes móveis ad hoc de múltiplos saltos. A análise revelou que o aumento do tráfego da rede reduz drasticamente a capacidade de transmissão de voz, que já se mostrava bastante limitada. A mobilidade provoca quebras de enlace devido à mudança de topologia, implicando um aumento no tamanho das perdas em rajada. Nos cenários simulados de múltiplos saltos, estas perdas consecutivas chegaram a 2.000 pacotes, enquanto nos cenários de comunicação direta este valor não passou de 90 pacotes consecutivos.

A técnica de diferenciação de serviço na subcamada MAC utilizada ofereceu duas classes de serviços com três níveis de prioridade. Apesar de conseguir uma redução do valor da variação do atraso da classe de maior prioridade, esta técnica não se mostrou muito eficiente em relação à taxa de perda, pois a diferenciação obtida não foi suficiente para proporcionar um aumento significativo do número de fontes de voz.

Alguns trabalhos futuros incluem a comparação com outros protocolos de roteamento para redes ad hoc, a utilização de outros mecanismos de provisão de qualidade de serviço e a avaliação do impacto do reconhecimento (ACK) do padrão IEEE 802.11 na capacidade de transmissão da rede.

Por fim, destaca-se a importância da existência de um mecanismo de controle de admissão distribuído, com o objetivo de limitar o número de estações transmitindo voz, impedindo que o excesso de usuánios inviabilize qualquer tipo de transmissão de tráfego de tempo-real.

\section{AGRADECIMENTOS}

Este trabalho foi realizado com recursos da FUJB, CNPq, CAPES, COFECUB e FAPERJ.

\section{REFERÊNCIAS}

[1] R. Sivakumar, P. Sinha e V. Bharghavan, "CEDAR: a coreextraction distributed ad hoc routing algorithm", in IEEE Infocom, Nova Iorque, EUA, março de 1999.

[2] A. Iwata, C.-C. Chiang, M. G. G. Yu e T-W., "Scalable routing strategies for ad hoc wireless networks", IEEE Joumal on Selected Areas in Communications, vol. 17, no. 8, pp. 13691379, agosto de 1999.

[3] S. Chen e K. Nahrstedt, "Distributed quality-of-service routing in ad hoc networks", IEEE Joumal on Selected Areas in Communications, vol. 17, no. 8, pp. 1488-1505, agosto de 1999.
[4] H. Xiao, W. K. G. Seah, A. Lo e K. C. Chua, "A flexible quality of service model for mobile ad-hoc networks", in IEEE Vehicular Technology Conference (VTC Spring 2000), Tóquio, Japāo, maio de 2000.

[5] A. V. Gahng-Seop Ahn, Andrew T. Campbell e L.-H. Sun, "SWAN: Service differentiation in stateless wireless ad hoc networks", in IEEE Infocom, Nova Iorque, EUA, junho de 2002.

[6] S.-B. Lee e A. T. Campbell, "INSIGNIA: In-band signaling support for QoS in mobile ad hoc networks", in 5 th Imernational Workshop on Mobile Multimedia Communications (MoMuC98), Berlim. Alemanha, outubro de 1998.

[7] J. Tsai e M. Gerla, "Multicluster mobile multimedia radio network", ACM-Baltzer Jounal of Wireless Nenvorks, vol. 1, no. 3, pp. 255-265, 1995.

[8] H.-K. Wu e P.-H. Chuang, "Dynamic QoS allocation for multimedia ad hoc wireless networks", Mobile Networks and Applications, vol. 6, no. 4, pp. 377-384, 2001.

[9] I. Aad e C. Castelluccia, "Differentiation mechanisms for IEEE 802.11", in IEEE Infocom. Anchorage, Alasca, abril de 2001.

[10] M. G. Rubinstein e J. F. de Rezende, "Qualidade de serviço em redes 802.11", in XX Simpósio Brasileiro de Redes de Computadores (SBRC2002), Búzios, RJ, Brasil, maio de 2002.

[11] A. Köpsel e A. Wolisz, "Voice transmission in an IEEE 802.11 WLAN based access network", in Workshop on Wireless Mobile Multimedia (WoWMoM'2001), Roma, Itália, julho de 2001.

[12] A. Köpsel, J.-P. Ebert e A. Wolisz, "A performance comparison of point and distributed coordination function of an IEEE 802.11 WLAN in the presence of real-time requirements", in Workshop on Mobile Multimedia Communications (Mo$M u C 2000$ ), Tóquio, Japāo, outubro de 2000.

[13] P. B. Velloso, M. G. Rubinstein e O. C. M. B. Duarte, "Analyzing voice transmission capacity on ad hoc networks", in International Conference on Communications Teclmology (ICCT 2003), Pequim, China, abril de 2003.

[14] P. B. Velloso, M. G. Rubinstein e O. C. M. B. Duarte, "Uma análise da capacidade da transmissão de voz em redes ad hoc", in XXI Simpósio Brasileiro de Redes de Computadores (SBRC2003), Natal, RN, Brasil, maio de 2003.

[15] ITU-T, "One-way transmission time", in Recomendaçäo G.114, março de 1993.

[16] IEEE, Standard 802.11, Wireless LAN medium access control (MAC) and physical layer (PHY) specifications - Part 11, 1999.

[17] B. P. Crow, F. Indra Widjaja, J. G. Kim e P. T. Sakai, "IEEE 802.11 wireless local area networks", IEEE Communications Magazine, vol. 35, no. 9, pp. 116-26, setembro de 1997.

[18] K. Fall e K. Varadhan, The ns Manual. UC Berkeley, LBL, USC/ISI, and Xerox PARC, abril de 2002. Disponível em http://www.isi.edu/nsnam/ns/ns-documentation.html.

[19] D. B. Johnson, D. A. Maltz, Y.-C. Hu e J. G. Jetcheva, The Dynamic Source Routing Protocol for Mobile Ad Hoc Nenworks (DSR), fevereiro de 2002. Internet draft.

[20] P. Brandy, "A technique for investigating on/off patterns of speech", Bell Labs Tech Jounnal, vol. 44, no. 1, pp. 1-22, janeiro de 1965.

[21] A. Markopoulou, F. Tobagi e M. Karam, "Assessment of VoIP quality over intemet backbones", in IEEE Infocom, Nova Iorque. EUA, junho de 2002.

[22] S. R. Das, C. E. Perkins e E. M. Royer, "Performance comparison of two on-demand routing protocols for ad hoc networks", in IEEE Infocom, pp. 3-12, março de 2000. 
Pedro Braconnot Velloso nasceu no Rio de Janeiro, Brasil, em 11 de janeiro de 1977. Obteve o título de Engenheiro Eletrônico pela Universidade Federal do Rio de Janeiro (UFRJ), Brasil, em 2001. Pela COPPE/UFRJ, obteve o título de Mestre em Ciências em Engenharia Elétrica em 2003. Atualmente é pesquisador bolsista do CNPq pelo projeto QUARESMA no Grupo de Teleinformática e Automação. Desenvolve pesquisas em redes móveis, agentes móveis, gerenciamento de redes e aplicações multimídias.

Marcelo G. Rubinstein nasceu no Rio de Janeiro. Brasil, em 29 de agosto de 1971. Obteve o título de Engenheiro Eletrônico pela Universidade Federal do Rio de Janeiro (UFRJ), Brasil, em 1994. Pela COPPE/UFRJ, obteve os títulos de Mestre em Ciências em Engenharia Elétrica e Doutor em Ciências em Engenlıaria Elérica em 1996 e 2001, respectivamente. Esteve realizando um doutorado sanduíche no Laboratório PRiSM da Université de Versailles StQuentin en Yvelines, França, de janeiro a setembro de 2000. Foi pesquisador bolsista da FAPERJ, de dezembro de 2001 a fevereiro de 2002, alocado no Departamento de Eletrônica e de Computação da Escola de Engenharia da UFRJ, mais precisamente no Grupo de Teleinformática e Automação. Atualmente é Professor Adjunto da Universidade do Estado do Rio de Janeiro. Desenvolve pesquisas em redes móveis, agentes móveis, gerenciamento de redes e aplicações multimídias.
Otto Carlos M. B. Duarte Otto Carlos M. B. Duarte nasceu no Rio de Janeiro en 23 de outubro de 1953. Recebeu os diplomas de Engenheiro Eletrônico e de Mestre em Engenharia Elétrica pela Universidade Federal do Rio de Janeiro, em 1976 e 1981 , respectivamente, e o título de Dr. Ing. pela École Nationale Supérieure des Télécommunications, França, en 1985. Realizou pós-doutoramentos no laboratório MASI da Universidade Paris 6 , em 1992/93, e no International Computer Science Institute (ICSI) associado à Universidade da Califórnia em Berkeley, em 1995. É Professor Titular da Universidade Federal do Rio de Janeiro. Foi professor convidado da Universidade Paris 6 en 1999 e 2001. Lidera o Grupo de Teleinformática e Automação (GTA) da CoppePoli/UFRJ. Seus principais interesses em pesquisa são em protocolos de alta velocidade, comunicaçōes multimúdias, redes móveis, qualidade de serviço e segurança na Internet. 